\title{
Teaching Simulator Development Based on Finite State Machine and Big Five Personality
}

\author{
Wawan Setiawan ${ }^{1}$, Siti Fatimah ${ }^{2}$, Enjun Junaeti ${ }^{3}$, Jajang Kusnendar ${ }^{4}$, Rasim ${ }^{5}$, M. Eagan \\ Ramadhan $^{6}$, Ria Anggraeni ${ }^{7}$, Joy M. Suba ${ }^{8}$, Edwin D. Torres ${ }^{9}$, Maynard Jay S. Galang ${ }^{10}$ \\ \{wawans@upi.edu ${ }^{1}, \underline{\text { sitifatimah@ } u_{\text {upi.edu }}^{2} \text {, enjun@upi.edu }{ }^{3}, \text { jkusnendar@upi.edu }}$, rasim@upi.edu ${ }^{5}$, \\ ria.anggraeni@upi.edu $\left.{ }^{7}\right\}$
}

Computer Science, Universitas Pendidikan Indonesia, Bandung, Indonesia ${ }^{1,3,5,6,7}$ Mathematic, Universitas Pendidikan Indonesia, Bandung, Indonesia ${ }^{2}$ Computer Science Education, Universitas Pendidikan Indonesia, Bandung, Indonesia ${ }^{4}$ Computer Science, University of Assumption, Manila, Philippines ${ }^{8,9,10}$

\begin{abstract}
Teaching Simulator is an application for teachers in the form of teaching simulation games. The teacher will be in a virtual class and interact with virtual students. Students have different characteristics based on the Big five Personality method and are created with the AI approach in the form of Finite State Machine. The teacher has one character based on a teaching approach. The end of the game is the achievement of teaching that shows the level of understanding and skills of players in carrying out teaching. We uses Research and Development Methods, the validity of the application use the learning object review Instrument (LORI), and the acceptance level of the application using the rating scale. The results showed that the application qualification was $94 \%$, a very good category. The results of the game show an increase in teaching attainment of $78 \%$ to $93 \%$ with a frequency of games 5 times.
\end{abstract}

Keywords: Teaching Simulator, Finite State Machine, Big Five Personality

\section{Introduction}

Teaching skills are one that must be understood in developing learning. Education students need training and teaching exercises that must be facilitated including the application teaching simulator. Application teaching simulator is a virtual class for teaching exercises such as games to achieve the cognitive and affective abilities of students. Players as teachers who can interact with students, make decisions, and receive feedback from the system [1].

Virtual student characters in the teaching simulator were created with artificial intelligence (AI) approach that is able to make adaptive decisions in Finite State Machine (FSM) that can represent behaviors like real students with different personalities based on the big five personality method [2].

FSM represents student behavior such as attention, sleepiness, sleep, boredom, and others. Each state is related to other states and is associated with the transition. Each transition leads from one state to another through action. The transition has a set of conditions so that the state is fulfilled, if the condition of a transition is fulfilled, the behavior/state of the student will change to the intended behavior/state (action). Setting the conditions of each transition using the Big Five Personality method consisting of 5 indicators are neuroticism, extraversion, 
openness, agreeableness, and conscientiousness (OCEAN). Big five has the breadth and level of abstraction theory so that it can represent the personality of each student in general [3].

\section{Finite State Machine}

The finite state machine is used to make student behavior based on the amount of cognitive, affective, curiosity, and teacher actions. Student cognitive is related to students' understanding of learning material (see Figure 1).

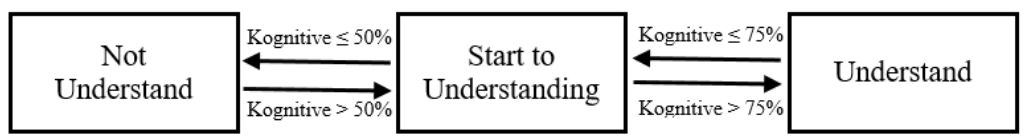

Fig. 1. Finite state machine based on cognitive student behavior.

Cognitive behavior of students includes not understanding, starting to understand, and already understand. If cognitive is less than 50\%, students don't understand, if cognitive is between $50 \%-75 \%$, students will understand, and if cognitive is more than $75 \%$, students will understand. Each state is displayed in the form of student animation on the application.

Affective is related to students' moods, affective behaviors of students include drowsiness, neutrality, and pleasure. If effective is less than $20 \%$ then students are sleepy, if effective between $20 \%-60 \%$ then students behave normally, and if affective is more than $60 \%$ then students are happy.

The teacher changes the behavior of students to be happy, or cheerful so that increased enthusiasm for learning. When the student's curiosity is worth $100 \%$, the student will ask and when the question has been answered curiosity becomes $0 \%$ and the student's behavior will change according to the number of effective obtained.

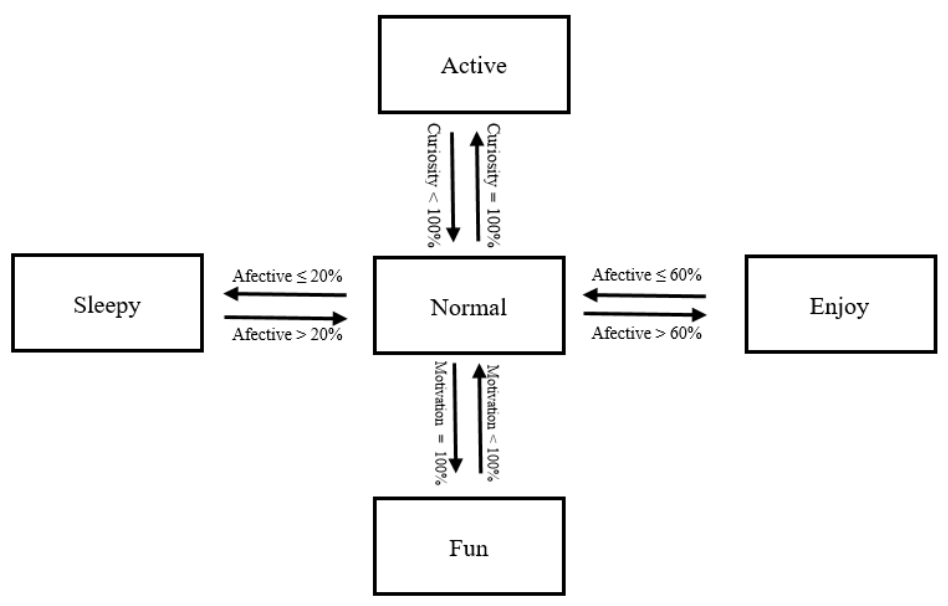

Fig. 2. Finite state machine based on affective student behavior. 
Cognitive and Affective each student changes as the game goes on. This change depends on the activity of the teacher and is controlled by cognitive and affective speed functions as follows.

$$
\begin{aligned}
K & =\frac{C}{10} \times T / S \\
K & =O X C \\
A & =-\frac{N}{10} \times C / S \\
A & =\frac{E}{10} \times C / S \\
A & =\frac{a}{10} \times C / S \\
I & =\frac{O}{10} \times C / S
\end{aligned}
$$

Equation (1) is the cognitive rate when the teacher explains and writes, $\mathrm{K}$ is a cognitive increase, $\mathrm{C}$ is the value of conscientiousness of students' big five personality, and $\mathrm{T}$ is a constant based on student learning type if the activity is in accordance with the student's learning type it is worth 1.5, if it is not worth 1 , and $\mathrm{S}$ is per second. Equation (2) is the cognitive rate when the teacher explains and writes, $\mathrm{K}$ is a cognitive increase, $\mathrm{O}$ is student openness value, and $\mathrm{C}$ is 1 value constant. Equation (3) is the rate of effective when the teacher is silent, explains, and writes, $\mathrm{A}$ is an effective increase, $\mathrm{N}$ is the value of neuroticism of students' big five personalities, $\mathrm{C}$ is a constant worth 0.75 , and $\mathrm{S}$ is a unit per second. Equation (4) is the effective rate when the teacher jokes, $\mathrm{A}$ is the effective increase, $\mathrm{E}$ is the extraversion value of the students' big five personalities, $\mathrm{C}$ is the constant valued at 2.25, and $\mathrm{S}$ is the unit per second. Equation (5) is the effective rate when the teacher is absent, $\mathrm{A}$ is an effective increase, a is the value of agreeableness of a student's big five personalities, $\mathrm{C}$ is a constant of value 1, and $\mathrm{S}$ is a unit per second. Equation (6) is the rate of curiosity, Student curiosity increases when the teacher explains or writes. $\mathrm{I}$ is an increase in curiosity, $\mathrm{O}$ is the openness value of the big five personalities of students, $C$ is a constant of value 4 , and $S$ is a unit per second.

\section{Research Method}

The research method used is research and development with the waterfall model which includes needs analysis, application design, implementation (programming), testing, validation, and implementation. Analysis of game requirements is student character, learning character, and teacher character. The game is designed as a learning path with the atmosphere of a virtual classroom. Implementation is carried out using the Android Unity Platform. Trials are conducted on educational students who have received educational courses. Application validation is done by media experts and content using the Learning Object Review Instrument (LORI), and the acceptance level uses a rating scale. After repairs based on the results of the trial and validation, the packaging is then carried out for use. Teaching simulators are applied to educate students in various classes by sampling with frequencies more than once. The effectiveness of the application of games in terms of various aspects, namely time, the 
achievement of positive aspects, the achievement of affective aspects, and performance qualifications of teachers or users.

\section{Results and Discussion}

\subsection{Media Teaching Simulator}

The media teaching simulator produced is a teaching simulation game that is controlled by the player as a teacher. The course of the game is a series of learning that is delivered by a teacher ranging from attendance to students achieving cognitive and affective understanding. At the end of the game, the level of cognitive and affective achievement is expressed which shows the level of success of learning or learning qualifications. The game can be terminated by the system or by the player himself and every end there is a result. The following is an example of a game teaching simulator interface which is a standard series of learning events ranging from opening to closing. But this game teaching simulator has not included student evaluation events.

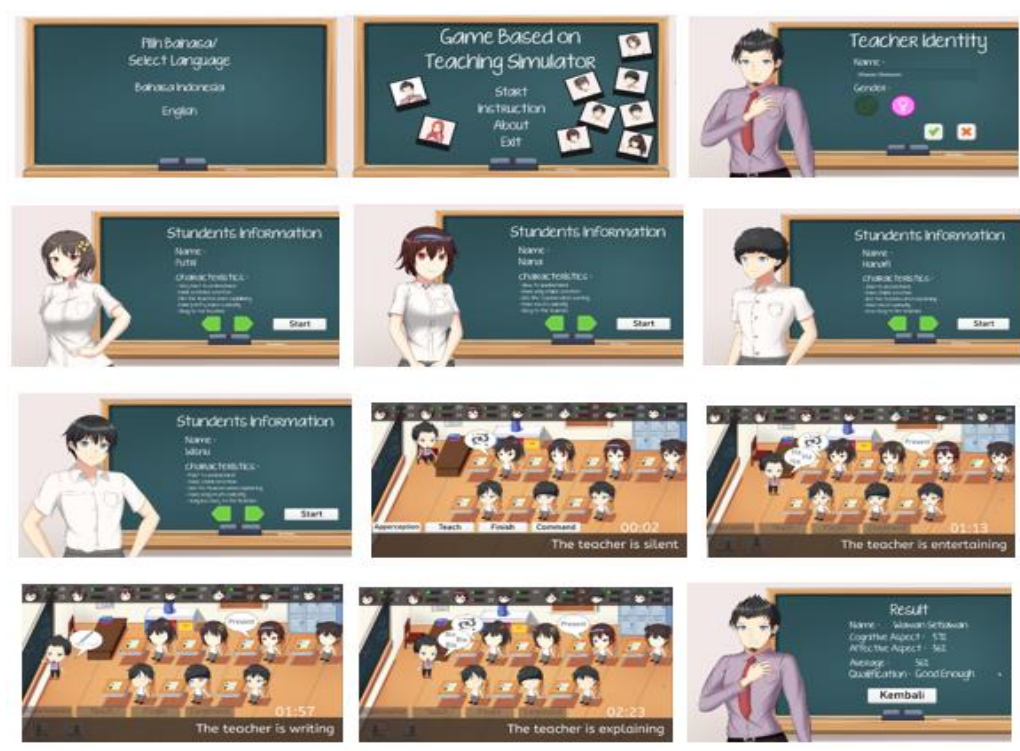

Fig. 3. The Interface of Stage of The Game.

\subsection{Validation of the Media Teaching Simulator Application}

The validity of the media teaching simulator is done by experts using the learning object review instrument (LORI). After calculating the number of scores from each question and every aspect, the data on the value of each aspect is divided by the ideal value of each aspect and used as a percentage so that it can be categorized. After the validity test, the data obtained from the instrument is processed and analyzed using the rating scale method with the following equation. 
Note

$$
P=\frac{\text { Experts Score }}{\text { Ideal Score }} \times 100 \%
$$

Numbers

Ideal Score: The highest score for each item x Number of items x Number of respondents The category of calculation of percentage figures for each aspect uses Table 1 as follows.

Table 1. Category Rating Scale [7].

\begin{tabular}{ll}
\hline Score $(\boldsymbol{\%})$ & Category \\
\hline $\mathrm{P} \leq 20 \%$ & Very less \\
$20 \%<\mathrm{P} \leq 40 \%$ & Less \\
$40 \%<\mathrm{P} \leq 60 \%$ & Enough \\
$60 \%<\mathrm{P} \leq 80 \%$ & Good \\
$80 \%<\mathrm{P} \leq 100 \%$ & Very good \\
\hline
\end{tabular}

The results of expert validation are generally stated that the application of media teaching simulator is in the very good category an average of $94 \%$ with details such as Table 2 as follows.

Tabel 2. The validity of the Teaching Simulator Game Application.

\begin{tabular}{lccccc}
\hline \multicolumn{1}{c}{ Aspect } & $\begin{array}{l}\text { Number of } \\
\text { Questions }\end{array}$ & $\begin{array}{c}\text { Ideal } \\
\text { Score }\end{array}$ & $\begin{array}{l}\text { Expert } \\
\text { Score }\end{array}$ & $\begin{array}{l}\text { Percent } \\
\text { age }\end{array}$ & Category \\
\hline Content Quality & 3 & 75 & 65 & $87 \%$ & Very good \\
Learning Goal Alignment & 2 & 50 & 50 & $100 \%$ & Very good \\
Feedback and Adaptation & 2 & 50 & 50 & $100 \%$ & Very good \\
Motivation & 2 & 50 & 45 & $90 \%$ & Very good \\
Presentation Design & 4 & 100 & 95 & $95 \%$ & Very good \\
Interaction Usability & 3 & 75 & 70 & $93 \%$ & Very good \\
Accessbility & 2 & 50 & 50 & $100 \%$ & Very good \\
Reusability & 1 & 25 & 20 & $80 \%$ & Good \\
Standar Accompliance & 1 & 25 & 25 & $100 \%$ & Very good \\
\hline \multicolumn{1}{c}{ Average } & & & & $\mathbf{9 4 \%}$ & \\
\hline Aspects of & & & & &
\end{tabular}

Aspects of Learning Goals Alignment, Feedback and Adaptation, Accessibility, and Accomplice Standards show very well, perfect categories. These aspects indicate that the game has the clarity of purpose or game target, adaption and fast response, and the standard of game completeness. Aspects that are still low even though the categories are good and very good are content and usability. Content aspects have not been optimized and highlight activities. The aspect of usability really needs to be improved to practice and train the skills of educational students in managing learning classes. The other aspects are categorized as very good although not perfect. 


\subsection{Use of the Teaching Simulator Game Application and Duration of Game}

The application of game teaching simulators is carried out in an educational study program for three levels of educational students. Every level of students has a pedagogical understanding that varies according to the applicable curriculum. The youngest students have not obtained many educational courses, while the oldest students have obtained more education courses. The following are the game user data in this study as shown in Tables 3 and 4 below.

Table 3. Educational Students as Users.

\begin{tabular}{cccccc}
\hline Year & Male & Female & Practic & No. Practic & Sum \\
\hline 2014 & 2 & 3 & 5 & 0 & 5 \\
2016 & 18 & 13 & 0 & 31 & 31 \\
2017 & 9 & 7 & 0 & 16 & 16 \\
Sum & 29 & 23 & 5 & 47 & 52 \\
\hline
\end{tabular}

Table 4. Average of Game Time.

\begin{tabular}{cccc}
\hline Class & $\begin{array}{c}\text { Time-1 } \\
\text { (Second) }\end{array}$ & $\begin{array}{c}\text { Time-2 } \\
\text { (Second) }\end{array}$ & $\begin{array}{c}\text { Time-3 } \\
\text { (Second) }\end{array}$ \\
\hline 2014 & 4,00 & 4,00 & 4,00 \\
2016 & 4,32 & 4,32 & 4,66 \\
2017 & 4,51 & 4,41 & 4,72 \\
\hline
\end{tabular}

Characteristics of users are distinguished by level but not evenly distributed, gender is almost the same, has practiced more, and not yet practiced is still small. The maximum duration provided by the game application is 5 minutes, but the user can end the game before 5 minutes when it's finished. The following is the time the game is used by the user.

In general, users don't find it difficult to operate teaching in games, and most users are finished in less than a maximum of 5 minutes. Old-level students are students who almost complete their studies and already have complete abilities so that their average usage time is relatively fast. While the 2016 class has practiced teaching, but they need a relatively long time compared to the class of 2014. For the 2017 class, new students need more time compared to the two classes of 2016. This shows that senior students are more confident in managing to teach even though not necessarily the result is better because it is not careful.

\subsection{Cognitive and Affective Aspect Achievement}

The maximum cognitive aspect and affective aspect provided by the game is $100 \%$, and users can try to achieve it by playing instructions and teaching buttons. The following is the achievement of cognitive and affective aspects by the user.

The cognitive aspects of the 2016 and 2017 classes are relatively the same while 2014 is lower. On the other hand, in the case of 2014 class pedagogical competence is relatively higher, this can be understood as an element of carelessness. In the game, the element of carelessness can determine the final result. The 2014 class students are based on time and they finish quickly enough, but the results are relatively lower, while the two classes because they feel they do not 
have complete pedagogical skills, are more careful. Affective aspects are almost the same in 2016 and 2017, relatively the same while 2014 is lower. Angoatan 2014 is based on time and they finish quickly enough, but the results are relatively lower, while the two classes because they feel they do not have complete pedagogical skills, are more careful.

Table 5. Achievement of Cognitive Aspect.

\begin{tabular}{cccc}
\hline Class & Coginitive-1 & Coginitive-2 & Coginitive-3 \\
\hline 2014 & $71 \%$ & $71 \%$ & $71 \%$ \\
2016 & $99 \%$ & $96 \%$ & $95 \%$ \\
2017 & $89 \%$ & $97 \%$ & $100 \%$ \\
\hline
\end{tabular}

Table 6. Achievement of Affective Aspect.

\begin{tabular}{cccc}
\hline Class & Affective-1 & Affective -2 & Affective -3 \\
\hline 2014 & $59 \%$ & $59 \%$ & $59 \%$ \\
2016 & $84 \%$ & $87 \%$ & $91 \%$ \\
2017 & $72 \%$ & $92 \%$ & $96 \%$ \\
\hline
\end{tabular}

\section{Conclusion}

This research has developed game software for pedagogical learning, hereinafter referred to as game teaching simulators, which can be used by educational students in particular, teachers, and even the public. The teaching software of this game is still version 1.0 with an emphasis on the characteristics of students with finite state machines which consists of Mood, Understanding, Curiosity, and Compliance. The teaching software of this game has been dynamically developed with the mobile approach using the unity platform developed by Unity Technologies and used in developing games for PCs, consoles, cellphones and the web. The teaching software of this game is easy to operate and is able to create a fun playing learning with results that can be measured in positive, affective aspects.

Acknowledgments. This research is a collaboration between researchers from Universitas Pendidikan Indonesia (UPI) and the University of Assumption (AU) Philippines. We would like to thank the Chancellor and Dean of FPMIPA UPI and the President and Dean of Computer Science UA who facilitated this collaboration.

\section{References}

[1] Vu, M. C., \& Herbst, P.: Designing an intelligent teaching simulator for learning. (2010)

[2] Millington, I.: Metode Penelitian Kuantitatif Kualitatif dan R\&D. Morgan Kaufmann Publishers (2006) 
[3] Pervin, A. L., Cervone, D., \& John, O. P.: Psikologi Kepribadian : Teori dan Penelitian. Kencana (2010)

[4] Santerre, N., Blondel, F., Racoussot, F., Laverdure, G., Karpf, S., Dubois, P., \& Rouland, J.: A Teaching Medical Simulator: Phacoemulsification in Virtual Reality. Journal Francais D'ophtalmologie (2007)

[5] Fatimah, S., Setiawan, W., Kusnendar, J., Anggraeni, R., \& Junaeti, E.: Teaching Simulator for Development of Profesional Teacher. International Seminar on Mathematics, Science, and Computer Science Education (2015)

[6] Nestbit, J. C.: A Framework for Evaluating the Quality of Multimedia Learning Resource. (2007)

[7] Sugiyono.: Metode Penelitian Kuantitatif Kualitatif dan R\&D. Alfabeta (2012)

[8] Luengo, V., Mufti-Alchawafa, D., \& Vadcard, L.: Design of adaptive surgery learning environment with bayesian network. J In Proceedings of the 2007 International Technology, Education and Development Conference (2007) 